\title{
FREQUENCY OF VALPROIC ACID INDUCED THROMBOCYTOPENIA IN EPILEPTIC PATIENTS IN TERTIARY CARE HOSPITAL, FAISALABAD.
}

1. MBBS

Women Medical Officer

Allied Hospital, Faisalabad.

2. MBBS, FCPS

Assistant Professor

Faisalabad Medical University

3. MBBS, FCPS

Assistant Professor

Children Hospital \& ICH, Faisalabad.

4. MBBS, FCPS.

Associate Professor

Faisalabad Medical University.

5. MBBS

Women Medical Office

Allied Hospital, Faisalabad.

6. MBBS, FCPS

Professor of Paediatrics

Faisalabad Medical University.

Correspondence Address:

Dr. Zahid Mahmood Anjum

252-J Tech Town,

Satiana Road Faisalabad.

zmahmoodch@yahoo.com

Article received on:

08/01/2020

Accepted for publication:

$10 / 03 / 2020$

\section{INTRODUCTION}

Epilepsy may be defined as recurrent abnormal neuronal discharge leading to seizures or periods of unusual behavior, sensations and sometimes loss of awareness. Anyone can develop epilepsy and seizures in their lift time. It effects both male and females of all races, ethnic backgrounds and ages. ${ }^{1}$ Epilepsy contributes $10 \%$ of the global burden of brain disorders ${ }^{2}$ and is associated with considerable morbidity and mortality ${ }^{3}$ and poor quality of life. Worldwide, up to 80 million people are affected of whom 10.5 million are children $<15$ years. ${ }^{4}$ In Pakistan the prevalence of epilepsy is 9.99 per 1000 population and more cases of epilepsy are seen in people younger than 30 years. $^{5}$

Valproic acid is a widely-used first-generation antiepileptic drug, prescribed predominantly in epilepsy and psychiatric disorders. Valproic acid has good efficacy and pharmacoeconomic profiles, as well as a relatively favorable safety profile. However, adverse drug reactions have been reported in relation with valproic acid use, either as monotherapy or polytherapy with other antiepileptic drugs or antipsychotic drugs. ${ }^{6}$

Thrombocytopenia is a condition in which the blood has a lower than the normal platelet count. ${ }^{5}$ Normal platelet count is between 150000 and $450000 /$ ul of blood. Even though a platelet count of less than 150000/ul of blood is lower than normal, risk of mild bleeding occurs only when the platelet count falls below 50000/ul of blood. The risk of serious bleeding occurs when the level is below 20000ul of blood. ${ }^{7}$ Thrombocytopenia is one of the adverse effects of valproic acid therapy ${ }^{8}$, with incidence of $19.3 \% .^{5}$ The risk caused by thrombocytopenia can be easily prevented by promptly stopping the drug and monitoring the patient every week until the platelet count normalizes. ${ }^{7}$ 
No previous local study has been conducted on frequency of thrombocytopenia in epileptic patients taking valproic acid. We are conducting this study to identify the burden of side effect in our epileptic patients receiving valproic acid as monotherapy. An epileptic patient during a fit can sustain trauma, so the patients receiving valproic acid can be advised to look for bleeding and bruising along with regular monitoring of platelet count on follow up in hospital.

To see the frequency of thrombocytopenia in epileptic patients taking valproic acid.

Thrombocytopenia is defined as platelet count $<$ 150000.

\section{Epilepsy}

Epilepsy is $\geq 2$ unprovoked seizures more than 24 hours apart

\section{MATERIAL \& METHODS}

This was a Descriptive cross sectional conducted.

Indoor and outdoor patients of paediatric department of DHQ Hospital Faisalabad.

The duration of study was Six months period, from June 2017 to December 2017

The Sample Size was calculated By using WHO sample size calculator.

$P=19.3 \%$

Confidence level $=95 \%$

Absolute precision $=9 \%$

Sample size $=75$

Sampling Technique used was Non probability consecutive sampling

Inclusion Criteria

1. Generalized or focal epilepsy

2. Valproic acid monotherapy for longer than 6 months in the dose of $30 \mathrm{mg} / \mathrm{kg}$ or more.

3. Children of 2-12 years of age of both genders.

Exclusion Criteria

1. Patients with epilepsy using either combination therapy with valproic acid or other antiepileptic drugs.

2. Patients receiving anticoagulants/ antiplatelet drugs like Aspirin, warfarin, heparin, other NSAIDS.

3. Patients with diagnosed hematopoietic diseases like congenital anemia, congenital and acquired platelets diseases, malignancies.

After taking approval from hospital ethical review committee, 75 children of group 2 yrs to 12 yrs, irrespective of gender discrimination taking valproic acid for more than 6 months were enrolled from indoor and outdoor of paediatric department DHQ Hospital Faisalabad. Clinical data including age, gender, body weight, duration of valproic acid treatment, and daily dose of valproic acid was collected from parents on a proforma by myself. Children were excluded according to exclusion criteria. Parents were informed about the side effects of valproic acid especially thrombocytopenia and its effects on patient's daily life. Then after taking informed consent patient's blood sample was taken for complete blood count in standard vials and was sent to $\mathrm{DHQ}$ hospital pathology laboratory to diagnose thrombocytopenia as a count less than $150000 \mathrm{cmm}$, where reports were verified by pathologist.

All the data was analyzed by using SPSS version 20. Mean and standard deviation was calculated for all quantitative variable like age of patient, dose and duration of valproic acid therapy. Frequency and percentage was calculated for all qualitative variable like gender and type of epilepsy and thrombocytopenia. Effect modifiers like age, duration of therapy, gender, type of epilepsy and dose of valproic acid were controlled by stratification. Post stratification chisquare test was applied $p$-value $\leq 0.05$ was taken as significant.

\section{RESULTS}

In this study, the mean age of patients was $6.59 \pm 3.15 y e a r s$.

There were 43 (57.3\%) males and 32 (42.7\%) females. 
In this study, 34 (45.3\%) children had generalized type of epilepsy while $41(54.7 \%)$ had focal type of epilepsy.

The mean dose and duration of valproic acid treatment was $38.40 \pm 6.07 \mathrm{mg} / \mathrm{kg}$ and $3.15 \pm 2.82$ years respectively.

The mean platelet count after valproic acid treatment was 199602.87 $\pm 58058.85 \mathrm{mg} / \mathrm{dl}$.

In this study, only eighteen (24\%) children developed thrombocytopenia.

Data was stratified for age of children. In children aged 2-6years, thrombocytopenia was present in $6(17.1 \%)$ cases and in children aged $7-12$ years, thrombocytopenia was present in 12 (30.0\%) cases. The difference was insignificant $(p>0.05)$.

Data was stratified for gender of children. In male children, thrombocytopenia was present in $12(27.9 \%)$ children and in female children, thrombocytopenia was present in 6 (18.8\%) children. The difference was insignificant (p>0.05). Table-I

Data was stratified for type of epilepsy. In generalized type, thrombocytopenia was present in $8(23.5 \%)$ cases and in children with focal type, thrombocytopenia was present in 10 (24.4\%) cases. The difference was insignificant $(p>0.05)$. Table-II

Data was stratified for duration of valproic acid treatment. In children who had treatment for 1 -4years, thrombocytopenia was present in 11 (20.0\%) cases and in children who had treatment for 5-8years, thrombocytopenia was present in 7 $(35.0 \%)$ cases. The difference was insignificant (p>0.05). Table-III

Data was stratified for dose of valproic acid. In children who had $3040 \mathrm{~kg} / \mathrm{mg}$ dose, thrombocytopenia was present in 12 (24.5\%) cases and in children who had $41-50 \mathrm{mg} / \mathrm{kg}$ dose, thrombocytopenia was present in 6 (23.1\%) cases. The difference was insignificant $(p>0.05)$. Table-IV

\begin{tabular}{|l|c|c|c|c|}
\hline \multicolumn{2}{|c|}{} & \multicolumn{2}{c|}{ Gender } & \multirow{2}{*}{ Total } \\
\cline { 2 - 5 } & \multicolumn{2}{|c|}{ Male } & Female & \\
\hline \multirow{2}{*}{$\begin{array}{l}\text { Thrombocy- } \\
\text { topenia }\end{array}$} & Yes & $12(27.9 \%)$ & $6(18.8 \%)$ & $18(24.0 \%)$ \\
\cline { 2 - 5 } & No & $31(72.1 \%)$ & $26(81.3 \%)$ & $57(76.0 \%)$ \\
\hline Total & & $43(100 \%)$ & $32(100 \%)$ & $75(100 \%)$ \\
\hline
\end{tabular}

Table-I. Comparison of thrombocytopenia in both genders

Chi-square test $=0.843$, P-value $=0.358$ (Insignificant)

\begin{tabular}{|c|c|c|c|c|}
\hline & \multicolumn{2}{|c|}{ Type of Epilepsy } & \multirow{2}{*}{ Total } \\
\hline & & Generalized & Focal & \\
\hline \multirow{2}{*}{$\begin{array}{l}\text { Thrombocy- } \\
\text { topenia }\end{array}$} & Yes & 8 (23.5\%) & $10(24.4 \%)$ & $18(24.0 \%)$ \\
\hline & No & $26(76.5 \%)$ & $31(75.6 \%)$ & 57 (76.0\%) \\
\hline \multicolumn{2}{|l|}{ Total } & $34(100 \%)$ & 41 (100\%) & 75 (100\%) \\
\hline
\end{tabular}

Table-II. Comparison of thrombocytopenia in type of epilepsy

Chi-square test $=0.008$, P-value $=0.931$ (Insignificant)

\begin{tabular}{|c|c|c|c|c|}
\hline & \multicolumn{2}{|c|}{ Duration (Years) } & \multirow{2}{*}{ Total } \\
\hline & & $1-4$ & $5-8$ & \\
\hline \multirow{2}{*}{$\begin{array}{l}\text { Thrombocy- } \\
\text { topenia }\end{array}$} & Yes & $11(20.0 \%)$ & 7 (35.0\%) & $18(24.0 \%)$ \\
\hline & No & $44(80.0 \%)$ & $13(65.0 \%)$ & 57 (76.0\%) \\
\hline \multicolumn{2}{|l|}{ Total } & 55 (100\%) & $20(100 \%)$ & 75 (100\%) \\
\hline
\end{tabular}

Table-III. Comparison of thrombocytopenia in duration of treatment strata

Chi-square test $=1.809, \mathrm{P}$-value $=0.179$ (Insignificant)

\begin{tabular}{|l|c|c|c|c|}
\hline \multicolumn{2}{|c|}{} & \multicolumn{2}{c|}{ Dose $\mathbf{( m g / k g )}$} & \multirow{2}{*}{ Total } \\
\cline { 2 - 5 } & & $\mathbf{3 0 - 4 0}$ & $\mathbf{4 1 - 5 0}$ & \\
\hline \multirow{2}{*}{$\begin{array}{l}\text { Thrombocy- } \\
\text { topenia }\end{array}$} & Yes & $12(24.5 \%)$ & $6(23.1 \%)$ & $18(24.0 \%)$ \\
\cline { 2 - 5 } & No & $37(75.5 \%)$ & $20(76.9 \%)$ & $57(76.0 \%)$ \\
\hline Total & & $49(100 \%)$ & $26(100 \%)$ & $75(100 \%)$ \\
\hline
\end{tabular}

Table-IV. Comparison of thrombocytopenia in dose strata

Chi-square test $=0.019$, P-value $=0.892$ (Insignificant)

\section{DISCUSSION}

Antiepileptic drugs are the most common used treatment for epilepsy and seizures disorders. They help control seizures in about $70 \%$ of patients. The most common drug used is valproic acid. Valproic acid shows the most promising efficiency in treating mood as well as anxiety disorders and different types of seizures. ${ }^{9}$

In our study, the mean age of patients was $6.59 \pm 3.15$ years. There were 43 (57.3\%) males and 32 (42.7\%) females. The mean 
platelet count after valproic acid treatment was $199602.87 \pm 58058.85 \mathrm{mg} / \mathrm{dl}$. In this study, 18 (24\%) children had thrombocytopenia while 57 (76\%) did not develop thrombocytopenia. Thrombocytopenia is one of the adverse effects of valproic acid therapy ${ }^{8}$, with incidence of $19.3 \% .^{5}$

Thrombocytopenia is one of the most common side effects associated with valproic acid therapy, with incidence ranging from $1 \%$ to $30 \% .^{10,11}$ It is mild to transient in most cases which usually resolves spontaneously on dosage reduction or withdrawal of the drug. ${ }^{12,13}$ Available reports showed that thrombocytopenia associated with valproic acid therapy has been reported to resolve without interruption of valproic acid treatment and has also been reported to endure over time or to have an erratic course. ${ }^{11,14}$

Sahu et al., also showed that total percentage of thrombocytopenia was found to be $12.5 \%$ in epileptic children taking valproic acid. ${ }^{15}$ Delgado et al., found that $21 \%$ epileptic children taking valproate developed thrombocytopenia. Thus, the medication can be safely lowered in most patients with thrombocytopenia rather than discontinued altogether. Platelet counts should probably be monitored more carefully in patients known to have higher drug levels. ${ }^{12}$

Nasreddin and Beydoun conducted a study on 265 patients taking valproic acid for epilepsy. Of these, $17.7 \%$ of patients experienced thrombocytopenia after exposure to valproic acid. ${ }^{16}$

In our study, we stratified data for age of children. In children aged 2-6years, thrombocytopenia was present in $6(17.1 \%)$ cases and in children aged 7-12years, thrombocytopenia was present in 12 $(30.0 \%)$ cases. The difference was insignificant $(p>0.05)$. We stratified data for gender of children. In male children, thrombocytopenia was present in 12 (27.9\%) children and in female children, thrombocytopenia was present in 6 $(18.8 \%)$ children. The difference was insignificant $(p>0.05)$.

In this study, 34 (45.3\%) children had generalized type of epilepsy while 41 (54.7\%) had focal type of epilepsy. Data was stratified for type of epilepsy. In generalized type, thrombocytopenia was present in $8(23.5 \%)$ cases and in children with focal type, thrombocytopenia was present in 10 (24.4\%) cases. The difference was insignificant $(p>0.05)$.

In our study, the mean duration of valproic acid treatment was 3.15 \pm 2.82 years. Data was stratified for duration of valproic acid treatment. In children who had treatment for 1-4years, thrombocytopenia was present in 11 (20.0\%) cases and in children who had treatment for 5-8years, thrombocytopenia was present in 7 $(35.0 \%)$ cases. The difference was insignificant $(p>0.05)$.

In our study, the mean dose of valproic acid treatment was $38.40 \pm 6.07 \mathrm{mg} / \mathrm{kg}$. Data was stratified for dose of valproic acid. In children who had $3040 \mathrm{~kg} / \mathrm{mg}$ dose, thrombocytopenia was present in 12 (24.5\%) cases and in children who had $41-50 \mathrm{mg} / \mathrm{kg}$ dose, thrombocytopenia was present in $6(23.1 \%)$ cases. The difference was insignificant $(p>0.05)$.

\section{CONCLUSION}

Thus the frequency of thrombocytopenia is low. Now we have got the local evidence and it showed that the frequency is low. But still we will advise the patients to screen out themselves for bleeding or bruising then urgently present for confirmation of thrombocytopenia.

Copyright $@ 10$ Mar, 2020.

\section{REFERENCES}

1. Mikati MA, Hani A. Seizures in childhood. Kliegman RM, Stanton BF, Schor NF, St Geme JW, Behrman RE Nelson Textbook of Pediatrics Philadelphia, Saunders 2011; 19:2013-7.

2. Newton CR, Garcia HH. Epilepsy in poor regions of the world. The Lancet 2012; 380(9848):1193-201.

3. Sillanpää M, Shinnar S. SUDEP and other causes of mortality in childhood-onset epilepsy. Epilepsy \& Behavior 2013; 28(2):249-55.

4. Atugonza R, Kakooza-Mwesige A, Lhatoo S, Kaddumukasa M, Mugenyi L, Sajatovic M, et al. Multiple anti-epileptic drug use in children with epilepsy in Mulago hospital, Uganda: A cross sectional study. BMC pediatrics 2016; 16(1):34. 
5. Mehmood T, Saleem M, Shah SSH. Frequency of valproate induced thrombocytopenia in epileptic children. Jumdc July-December 2014; 5(2):52-6.

6. Nanau RM, Neuman MG. Adverse drug reactions induced by valproic acid. Clinical biochemistry 2013; 46(15):1323-38.

7. Nerumalla CS, Shah AA. A case of thrombocytopenia associated with valproic Acid treatment. The primary care companion for CNS disorders 2013; 15(4).

8. Tseng Y-T, Ho P-S, Wang C-F, Liang C-S. Valproic acid-induced thrombocytopenia may cause wound nonhealing in individuals with schizophrenia. Psychosomatics 2015; 56(4):410-3.

9. Eliopoulos H. Thrombocytopenia coincident with Depakote therapy. Abbott park, ill, Abbott pharmaceutical products division, professional information and product safety 1993.

10. Smith F, Boots M. Sodium valproate and bone marrow suppression. Annals of neurology 1980; 8(2):197-9.

11. May RB, Sunder TR. Hematologic manifestations of long $\square$ term valproate therapy. Epilepsia 1993; 34(6):1098-101.
12. Delgado MR, Riela AR, Mills J, Browne R, Roach ES. Thrombocytopenia secondary to high valproate levels in children with epilepsy. Journal of child neurology 1994; 9(3):311-4.

13. Winfield D, Benton P, Espir M, Arthur L. Sodium valproate and thrombocytopenia. British Medical Journal 1976; 2(6042):981.

14. Eastham R, Jancar J. Sodium valproate and platelet counts. British Medical Journal 1980; 280(6208):186.

15. Sahu J, Hishikar R, Sahu MK, Raut P, Bharti AK, Agrawal $S$. Occurrences of thrombocytopenia with valproic acid used for psychiatric indication. International Journal of Basic \& Clinical Pharmacology 2017; 4(4):765-9.

16. Nasreddine W, Beydoun A. Valproate $\square$ induced thrombocytopenia: A prospective monotherapy study. Epilepsia 2008; 49(3):438-45.

\begin{tabular}{|c|c|c|c|}
\hline \multicolumn{4}{|c|}{ AUTHORSHIP AND CONTRIBUTION DECLARATION } \\
\hline Sr. \# & Author(s) Full Name & Contribution to the paper & Author(s) Signature \\
\hline 1 & Anila Kanwal & 1st Author & \\
\hline 2 & Sumaira Hassan & 2nd Author & \\
\hline 3 & Zahid Mahmood Anjum & 3rd Author & \\
\hline 4 & Mehboob Alam Siddique & 4th Author & \\
\hline 5 & Faiza Idrees & 5th Author & Faiza felrees \\
\hline 6 & Hina Ayesha & 6th Author & $\overbrace{}^{\circ}$ \\
\hline
\end{tabular}

